\title{
Cuarto miliario bético de la serie Hadrianus Augustus fecit hallado fortuitamente en La Rinconada (Sevilla) \\ Fourth Roman milestone from Baetica of the series Hadrianus Avgustus Fecit preserved in the province of Seville
}

Sergio España Chamorro, Universidad Complutense de Madrid sergio.espana@ghis.ucm.es

Recibido: 01-02-2017

Aceptado: 12-09-2017

\section{Resumen}

Se presenta un miliario inédito hallado fortuitamente en La Rinconada (Sevilla) en 2014. Dicho miliario pertenece a una serie de la que se conocían tres ejemplares más. Aparte de presentar el epígrafe, el número de este ejemplar (I) permite hacer una hipótesis sobre el caput viae y la vía a la que pudieron pertenecer los miliarios de esta serie.

Palabras clave: Miliario romano, caput viae, vías romanas, Baetica.

\begin{abstract}
This article presents an unpublished milestone found by chance in the town of La Rinconada (Sevilla) in 2014. The quoted epigraph belongs to a series of three identical milestones already known. Taking this new milestone, whose number of mile (I) is the only one different from the others, allows me to launch the hypothesis about the caput viae and the road where the series would be placed.
\end{abstract}

Keywords: Roman milestone, caput viae, Roman roads, Baetica.

\section{INTRODUCCIÓN}

A finales de mayo de 2014, durante una ronda de inspección, una patrulla de la Guardia Civil entró en una finca de la localidad de La Rinconada (Sevilla) con el propósito de ver si se estaba produciendo algún acto delictivo en su interior. En dicha inspección se identificaron elementos constructivos contemporáneos (unas columnas "genovesas" llamadas así en la prensa y el informe del SEPRONA), además de un fuste de columna romano y lo que se identificó, desde un primer momento, como una inscripción en latín.

1 Agradezco encarecidamente a la patrulla del SEPRONA de la Guardia Civil de El Ronquillo (Sevilla) y, en especial, a su jefe, D. Sergio Pablos, por la información y fotografías proporcionadas, así como los derechos de publicación, además de su amabilidad al contestar a todas mis preguntas de
Siguiendo el protocolo habitual en estos casos, los miembros de la Guardia Civil avisaron a sus superiores, a la delegación del SEPRONA ${ }^{1}$ de la localidad de El Ronquillo (Sevilla) y a expertos en la materia de la Consejería de Educación, Cultura y Deporte de la Junta de Andalucía.

En julio de ese mismo año la noticia del hallazgo casual saltó a la prensa ${ }^{2}$. En ella se daban algunos detalles más sobre su hallazgo. Durante el mes de mayo, pocos días antes del descubrimiento de la pieza que aquí ocupa, un incendio afectó a la mencionada finca.

manera desinteresada, al igual que a $\mathrm{D}^{\mathrm{a}}$ Raquel Vega (concejal de Cultura y $1^{\circ}$ teniente de Alcalde del Ayuntamiento de La Rinconada) por la amabilidad prestada.

2 La Guardia Civil encuentra piezas romanas en los restos de un incendio, Diario de Sevilla 27/07/2014. 
El fuego calcinó una estructura de madera que protegía los materiales encontrados por la Guardia Civil, dejando al descubierto y a la intemperie la inscripción romana. Tras la valoración efectuada por los miembros de la Consejería, ésta fue catalogada como miliario y como tal se presentó en la prensa. Los restos encontrados fueron trasladados al Conjunto Arqueológico de Itálica para ser restaurados y custodiados y es allí donde actualmente se conservan a la espera de poder ser expuestos en su centro de interpretación. Sin embargo, pese a ser conocida por la prensa, la inscripción no había sido objeto de estudio como me indicó la Delegación de Cultura de la Junta de Andalucía y el Museo de Sevilla.

En cuanto a su procedencia, no se disponen de datos certeros. El propietario de la finca en donde se encontraba indicó a la Guardia Civil que su padre, que poseía una empresa de trabajos de construcción, había sido el responsable de su hallazgo y traslado. El informe proporcionado tras la investigación indica que dicha persona era "aficionado" a este tipo de piezas que iba obteniendo de las casas en las que trabajaba en Sevilla y alrededores, y después las trasladaba a la finca que poseía en La Rinconada (en el informe policial se cita la existencia de los otros restos anteriormente mencionados que fueron inspeccionados por los arqueólogos de la Junta de Andalucía, pero que debían de ser de escaso valor, como también indicaba la prensa). Los descendientes del descubridor apuntaron directamente a una procedencia de Sevilla capital como la opción más probable y de la provincia de Sevilla, en última instancia, ya que sus trabajos se circunscribieron al entorno inmediato de la capital. Sin embargo, no se puede contrastar esta información para conocer el lugar concreto debido al fallecimiento del contratista.

\section{ESTUdIO DE LA PIEZA}

Como ya he avanzado, se trata de un miliario de mármol blanco procedente de las canteras de Almadén de la Plata, provincia de Sevilla (Medidas: ca. (150$160 \mathrm{~cm})^{3}$ de altura x $55 \mathrm{~cm}$ de diámetro). Debido a las altas temperaturas que se debieron alcanzar en el

3 Al perder parte del coronamento superior, se ha perdido parte del soporte. No obstante, la altura sería más similar al miliario de la milla XXVI $(150 \mathrm{~cm})$ que el de la milla XXV $(195 \mathrm{~cm})$, según las medidas proporcionadas por Rodríguez, 2004: 565-566.

4 Primera noticia en Hernández, Sancho y Collantes (1955: 249); García y Bellido (1960: 119); Nierhaus (1966: 169); Corpora: HAE 2201 = ERIt 34, p. 193-195 =Silliéres $\left(1990 \mathrm{a}: \mathrm{n}^{\circ} 79\right)=$ CILA 5, $1040=$ Corzo-Toscano $\left(1992: \mathrm{n}^{\circ}\right.$ 48) $=$ Solana-Sagredo (2008: $\left.n^{\circ} 64\right)$.

5 En la Memoria de las Excavaciones de 1903, Collantes (1953: 226) indica que, junto al corral de la casa donde fue incendio, su estructura exterior se fragmentó en varios puntos, provocando grandes fracturas y afectando, en consecuencia, a la lectura de la inscripción. Una de estas fracturas atraviesa la cartela verticalmente y otra con forma curva provocó el desprendimiento de parte del soporte, afectando a la esquina inferior izquierda y al propio campo epigráfico, causando la pérdida de algunas letras. Además, por haber permanecido largo tiempo a la intemperie, la moldura y parte de la inscripción están muy erosionadas. Se puede añadir que los daños también han alcanzado a las molduras del coronamiento y del apoyo, no quedando restos de las mismas. La propuesta de edición es la siguiente:

1

I

$\begin{array}{ll} & \text { HADRIAN̦[VS] } \\ & \text { AVG(VSTVS) } \\ 4 & {[\text { F]ẸCIṬ }}\end{array}$

El texto se desarrolla en dos campos epigráficos: el numeral, en la parte superior del fuste, sin delimitar, y dentro de una cartela que enmarca el resto del texto; la cartela porta la titulatura, así como el verbo fecit, que refleja el acto evergético. La moldura que delimita el campo epigráfico está formada por un listel recto y un suave cimacio hacia el interior (los otros miliarios tienen una cartela con las mismas características (Vid. Rodríguez, 2004: 566, $\mathrm{n}^{\circ}$ I-36). Las letras son capitales cuadradas esculpidas a bisel, de buena factura, con altura regular a excepción del numeral de la primera línea (1. 1: $17 \mathrm{~cm}$; 1. 2-4: $8 \mathrm{~cm}$ ). Tanto por su ordinatio como por la cuidada paleografía, no hay lugar a dudas de que esta pieza fue realizada al mismo tiempo (invierno del 122-123, según Sillières, 1990a, nº 78 y 79) y en la misma officina lapidaria que los otros tres miliarios, por lo que correspondería a la misma política de amojonamiento de la vía. Este miliario sería, por tanto, el cuarto ejemplar de una misma serie que ya era conocida: el primero fue encontrado en una esquina del derruido castillo de Guillena ${ }^{4}$ (Sevilla), en donde servía de guardacantón hacia 1903-19085, mientras que los

encontrado este miliario, se encontraron restos de una calzada romana y, a pocos pasos, el postscenio. La vía fue vista por Fernández López (1903: VI), quien la describe del siguiente modo "Los mismos trabajadores descubrieron también una magnífica vía de seis metros de anchura, solada con gruesas losas de piedra jabaluna, por término medio de metros 0,15 de espesor, y de todas formas y tamaños..." además de indicar que la cloaca iba por debajo. García y Bellido (1964: 457) indica que el miliario se hallaría justo a la entrada de la ciudad. En ERIt 34, Canto indica que la misma vía fue excavada por Manuel Bendala en 1973 en un lugar muy próximo al citado por Fernández López. 
otros dos ejemplares fueron encontrados en Italica, uno $^{6}$ con la milla XXV documentado como hallazgo fortuito en 1942 en las cercanías del teatro (parece ser que en posición primaria) y otro $^{7}$ con la milla XXVI hallado durante las excavaciones efectuadas en los niveles de relleno en la fase de abandono del pórtico del teatro en 1990, próximo al muro de cierre (cuadrante norte, cuadrícula NM3). Rodríguez ${ }^{8}$ apuntó que el sector inferior estaba pulido, a diferencia de otros que están destinados a ser hundidos junto a la vía. Los miliarios de esta serie, incluido el que se está tratando aquí, presentan la moldura y la inscripción con una ejecución muy cuidada, algo sin parangón en Hispania9 .

A pesar de su mal estado, el texto del miliario que se estudia no parece dar margen a interpretación. Dicho texto, al igual que en los otros tres miliarios, tiene una serie de particularidades, en comparación al resto de miliarios hallados en la Baetica. Una es que la ubicación del numeral, situado en la zona superior, no es la habitual en los miliarios imperiales (Salinas y Palao, 2012: 273-274). Otra particularidad es la breve titulatura del miliario, como ya avanzaron Corzo y
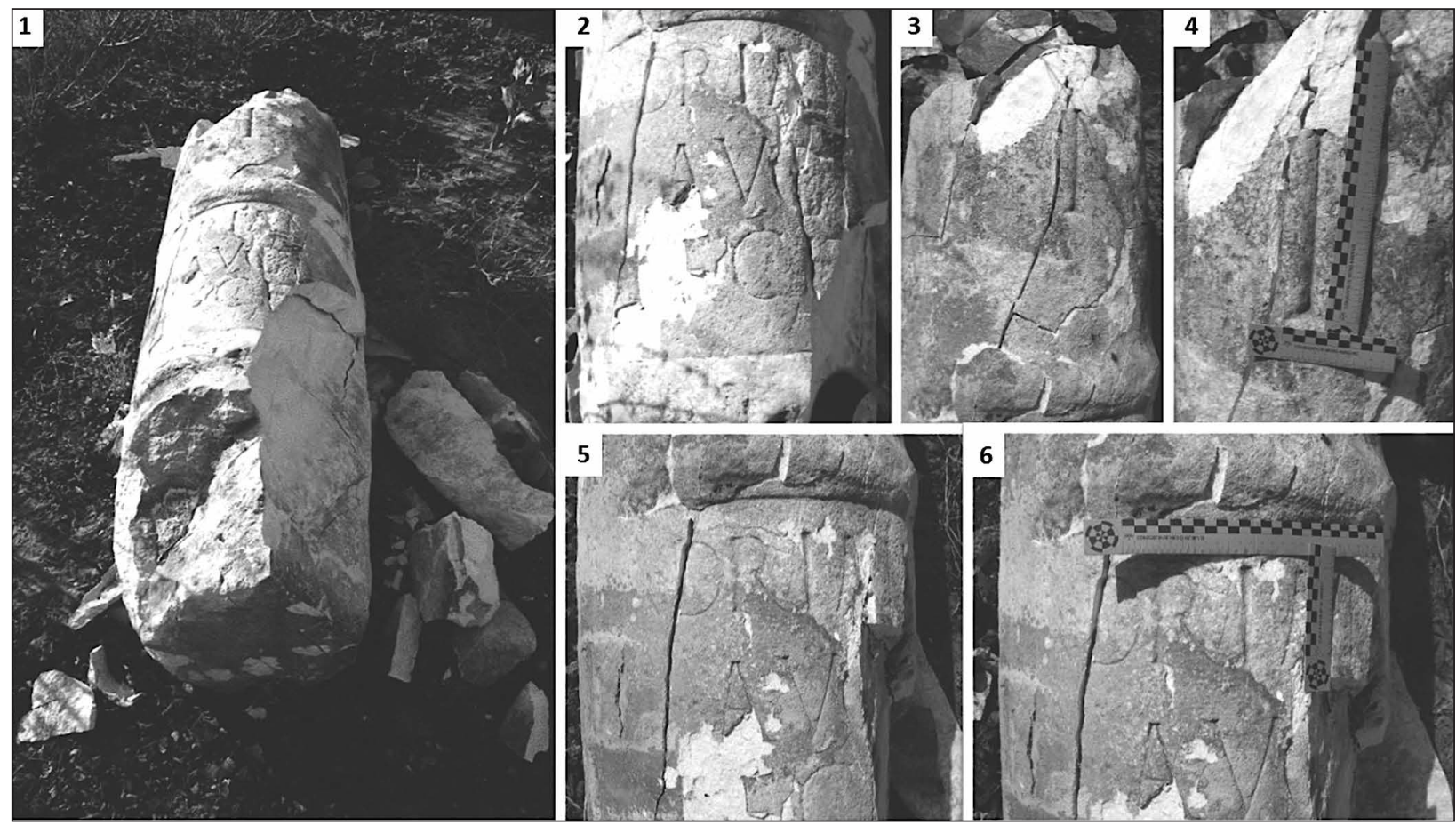

Fig. 1. Miliario en el momento del hallazgo 2. Cartela. 3. Numeral. 4. Numeral con medidas. 5. Cartela 6. Cartela con medidas. (Fotografías cedidas por el SEPRONA, Reportaje n ${ }^{0}$ 2014/100570/106 ${ }^{10}$ ).

6 Fernández Chicarro (1951: 83, no 69; 1957: 89, nº 69; 1969: 83); Fernández Chicarro y Fernández Gómez (1980: 92); Collantes (1953: 226 n 710); García y Bellido (1960: 75 y 119; 1965: 17-19, lam. III fig. 4); Nierhaus (1966: 195-196, lam. 58 ); Canto (1979: 334, lam 56a); Rodríguez (2004: 566 n ${ }^{\circ}$ I-37 y lam. F-48 XVII). Corpora: HAE 578, 1033 y $2200=$ ERIt $34=$ CILA 3, $367=$ Sillières $\left(1990 \mathrm{a}: \mathrm{n}^{\circ} 78\right)=$ Corzo y Toscano $\left(1992: \mathrm{n}^{\circ} 46\right)=$ SolanaSagredo (2008: $\left.n^{\circ} 65\right)$.

7 Corzo y Toscano (1989: lam. 101); Corzo (1993: 167 y fig. 20); Rodríguez (2004, 565 I-36 y lam. F-40 XVII) Corpora: Corzo-Toscano (1992: $\left.\mathrm{n}^{\circ} 47\right)=$ Solana y Sagredo (2008: 66) = HEp. 5, $708=$ HEp. 13, 615 .

8 Rodríguez (2004: 566, $\mathrm{n}^{\circ}$ I-36) indicó que el miliario italicense de la milla XXVI tenía oquedades en su límite inferior que afectaban a la moldura. Los otros dos miliarios estaban fragmentados por esa parte, por lo que no se pudo comprobar. Asimismo, el miliario recuperado de la finca de La Rinconada conserva parte de la zona inferior y no parece presentar esas oquedades, aunque sí el mismo acabado cuidado. En el caso de los dos miliarios italicenses podía estar justificado al haberse encontrado en la propia Italica lo que, quizás, era una señal de que ambos hubieran estado en las proximidades del entorno urbano. Con el miliario hallado casualmente en La Rinconada no se puede afinar su contexto, pero igual podía haber estado en las proximidades de un núcleo urbano. Esto puede dar la pista de que el miliario de la milla XXVI tuvo esas oquedades por algún tipo de reutilización posterior.

9 Es lo que Canto (en el comentario de HEp. 13, 615) denominó como "estilo urbano" y García y Bellido (1965: 297) "de corte y traza excepcionales" y "sin hipérbole, de lujo".

10 Desgraciadamente, no he podido tener ni acceso ni ulterior noticia de la pieza desde que entrase en las dependencias del Conjunto Arqueológico de Itálica, a pesar de haber intentado contactar con ellos sin ningún éxito. De ahí que las fotografías que se presentan no sean de la pieza restaurada. Desconozco si, a día de hoy (octubre de 2017), ha sido ya restaurado. 
Toscano (1992: 173-174) con respecto a los tres primeros miliarios, indica que no es el típico monumento honorífico ${ }^{11}$ caracterizado por toda la enumeración de nombres y títulos, sino que obedecería a una conmemoración de la vía, algo poco habitual ${ }^{12}$. Los mismos autores proponen que se tratase de una obra realizada por un "conciudadano", un monumento que sería un guiño a la mentalidad helénica de Adriano "más admiradora de la personalidad que de los títulos administrativos". Una última anotación debe hacerse con respecto a los miliarios de Adriano en la Baetica. Además de esta serie de cuatro miliarios, sólo existe uno más en toda la provincia, concretamente en Anticaria ${ }^{13}$, frente a los 68 hallados en el resto de la Península Ibérica ${ }^{14}$. El miliario de Anticaria tiene un texto claramente diverso, con un formulario similar a los miliarios del resto de emperadores. Esto marca una diferencia en el tratamiento de la figura del emperador italicense; una evolución de la que no se puede saber con certeza si es anterior o posterior a los cuatro miliarios del valle del Guadalquivir.

Sea como fuere, parece sorprendente el escaso número de miliarios adrianeos que se conservan, a pesar de la profusa actividad edilicia y propagandística que este emperador llevó a cabo en la Baetica.

\section{Comentario}

La buena fortuna de haber hallado la milla I de una serie de miliarios que se conoce desde hace más de 100 años no ha podido ser plena, al faltar datos concretos sobre su contexto que, a falta de futuras pistas, impide ofrecer una hipótesis fuera de dudas sobre la vía a la que pertenecieron estos miliarios y tampoco ofrecen una opción que no genere discusión ni dudas acerca de la ubicación de su caput viae, esto es, el lugar de ori-

11 No estoy indicando que no sea un monumento evergético y de propaganda, ya que creo que sería su función principal, más que informativa, como comenté en otras ocasiones (España-Chamorro 2017c; 2017d), sino que no este carácter honorífico diverge de la forma en la que es expresada en otros miliarios béticos.

12 Canto (HEp. 13, 615) dice que sería el mismo fenómeno con la inscripción de la orchestra del teatro de Italica (ERIt $49=$ CILA 3, $383=A E$ 1978, $402=$ HEp. 5, 720): L(ucius) B[la]ttius L(uci) f(ilius) Traianus Pollio G(aius!) T[raiu]s G(ai!) f(ilius) Pollio IIvir( $($ ) desig(nati) iter(um) pontific(es) prim [i cr]eati / Augusto orchestram pros[caeni]um itinera aras signa d(e) $s($ ua) p(ecunia) f(aciendum) c(uraverunt).

13 CIL II, $4694=$ = CIL II $2 / 5$, p. 205 = Sillières, 1990a: $\mathrm{n}^{\circ} 91=$ Corzo y Toscano, 1992: $\mathrm{n}^{\circ} 52$ = Solana y Sagredo, 2008: 63.

14 El CIL XVII/1 da un total de 13 para la Hispania Citerior sin la parte de Galicia (n ${ }^{\text {OS }}$ 62. 88. 154. 162. 172. 187. 192. 227. 241. 242. 269. 277. 296). Para esta zona, la recopilación de Rodríguez, Ferrer y Álvarez (2004) cuenta un total de 36 indicando que es el emperador del que mayor número de miliarios se han encontrado $\left(\mathrm{n}^{\mathrm{OS}}\right.$ 5. 58.62.81. 83.90. gen de la numeración (la milla 0) de la vía. Los escasos datos de su hallazgo tan sólo permiten aventurar otra hipótesis más.

La mayoría de los miliarios béticos ${ }^{15}$ correspondieron al amojonamiento llevado a cabo en la via Augusta (44 de las 76 columnas miliarias, aunque 5 son palimpsestos reutilizados, con lo que hay un total de 81 inscripciones en toda la provincia vid. el corpus en España-Chamorro, 2017a) y están siempre numerados partiendo desde el famoso arco del Ianus Augustus, emplazado muy probablemente en la llamada Venta del Arco (Mengíbar, Jaén, propuesto ahí por Sillières, 1994: 309). Sin embargo, es completamente descartable que estos cuatro miliarios de Adriano perteneciesen a la via Augusta, ya que tanto el lugar de aparición de los otros miliarios de la misma serie como el número de millas que citan, menor que el que tendrían que indicar de haberse numerado desde el arco de Jano, lo hacen imposible. Se sabe por otro miliario ${ }^{16}$ encontrado en el Puerto de Santa María (Cádiz) que esa via Augusta no tenía ningún caput viae intermedio en el territorio bético, como sí ocurre en el tramo de la Hispania Citerior, ya que el miliario gaditano también hace relación al Jano marcando CCXX[X]II millas que coincide grosso modo con el punto indicado.

Tampoco parece posible adscribirlos a la vía que va de Hispalis a Augusta Emerita, ya que sería extraño encontrar un caput en un lugar intermedio en una vía que se extiende por una misma circunscripción administrativa (la provincia y el mismo conventus) en contraposición a la numeración correlacional que la via Augusta sigue a través de los cuatro conventus iuridici. Corzo y Toscano citan un punto inexacto de la vía hacia Extremadura como caput de la misma $^{17}$, pero lo

124. 128. 138. 151. 190. 195. 200. 201.216. 238. 250. 275. 284. 296 (?). 331. 347. 382. 391. 427. 432. 445. 452. 463. 506. 536. 539. 540.541.554. 557) y aproximadamente 16 en Lusitania, Solana y Sagredo (2006: 35-86).

15 Casi un $60 \%$ del total durante los 4 siglos constatados en la epigrafía miliaria bética. Haciendo el cálculo sólo con los miliarios desde Augusto a Trajano, los cuales tienen unas características propias definidas (los miliarios de estos siglos llevan cómputo de millas y están emplazados mayoritariamente en la via Augusta y, más concretamente, en territorio del conventus Cordubensis, lo que podría incitar a pensar en una posible materia viaria para estas instituciones), las cifras aumentarían: 27 miliarios de un total de 29 para el siglo I (+90\%) y 3 de 6 del siglo II (50\%).

16 CIL II, 4734 = Sillières (1990a: $\left.\mathrm{n}^{\circ} 56\right)=$ Corzo y Toscano (1992: $\left.\mathrm{n}^{\circ} 31\right)$.

17 Nierhaus (1966) propuso un caput al norte de Guillena, sin más especificaciones. Corzo y Toscano (1992: 174), adscriben la creación de la vía Italica-Emérita a Adriano, cosa improbable, como bien indica Canto en HEp. 5, 708. 
cierto es que no existe ni una sola columna en todo el territorio de la Baeturia celtica ${ }^{18}$ que corresponda a un amojonamiento de esta o de otras vías en una o otra dirección ${ }^{19}$. De esta forma, hay que descartar la posibilidad de un caput emplazado en esa zona en donde, a decir verdad, no hay ningún punto de relevancia para condicionar las millas, sea además el elemento que rige unos miliarios que sólo parecen hallarse en el entorno del Baetis.

Por otro lado, Canto descartó que esta serie que aquí trato perteneciese tanto a la via Gades-HispalisEmerita, como la ab ostio fluminis Anae-Emeritam que revelan los itinerarios y propuso, ya en 1979, la teoría del caput viae en Ituci (Tejada la Vieja, Huelva) como única posibilidad que, teniendo en cuenta la situación geográfica de Italica, se encontrase a los $37 \mathrm{~km}$. que señala la inscripción miliaria hallada en el teatro ${ }^{20}$. Para el desarrollo de su teoría, Canto se basó en el término fecit como argumento irrebatible de indicación de una nueva vía que situase el miliario de Guillena después del de Italica basándose en la lectura de XXXI en vez de XXI.

Sin embargo, no han faltado voces contrarias a esta propuesta que creen más acertada una progresión norte-sur ${ }^{21}$ y que la progresión de millas hiciese que el miliario de Guillena tuviese un número menor que el

18 A excepción de una placa augustea que habla sobre la reparación de un puente en Encinasola (Huelva). Esta inscripción fue interpretada como miliario por Hübner (CIL II, 4686 = HEp . 7, 349). Luzón (1975: 291) ya indicó el traslado y los problemas que había supuesto la interpretación de Hübner, quien tenía dos copias. Ciertamente es una placa: Imp(erator) - Caesar · Au/gustus · Tr(ibunicia) . $p \cdot o \cdot($ testate $) \cdot X X X / p($ ontifex $) \cdot m($ aximus $) \cdot \operatorname{co}(n) s(u l) \cdot$ $\{X\} \cdot X I I I \cdot$ pater / patriae $\cdot f($ ecit $)(C I L$ II, $4686=E E$ IX, $413=$ ERBC $144=$ HEp. 7, 349).

19 Sin embargo, nada más pasar la frontera provincial en Los Santos de Maimona, en dirección a Augusta Emerita, se encuentran de nuevo miliarios anepígrafos. Por otra parte, la vía que une Arucci-Turobriga con Pax Iulia no tiene mojones en su parte bética, pero nada más pasar la mansio Fines (para mí, la frontera provincial) se encuentra un miliario de Adriano, Sillières (1990a: $\mathrm{n}^{\circ} 88$ ); HEp. 4, 1001; ERBC, $\mathrm{n}^{\circ}$ 197. Esto demuestra tendencias diversas en ámbitos administrativos diferentes. Vid. España-Chamorro, 2018.

20 En su estudio del acueducto de Italica, Canto (1979: 334) ya propuso que se pudiese tratar de esta vía, poniéndola en relación directa con el acueducto y con la necesidad de que éste tuviera una vía cercana, según cuentan los gromáticos. Esta teoría revisada y ampliada en ERIt 34 además de sus comentarios en HEp. 5, 708 y 13, 615.

21 Frente a la propuesta de Canto: Nierhaus (1966: 195-196); Sillières (1984: 273; 1990a: no 78-79); Stylow, Atencia y Páez (2004a: 361-378); Stylow, Atencia y Páez (2004b: de Italica. Por mi parte, creo que puede descartarse la lectura XXXI si comparamos la distribución del texto de los miliarios completos (fig. 2). Como se puede ver que, a pesar de ligeras diferencias entre unos y otros, guardan una perfecta composición simétrica entre el numeral (lín. 1) y el resto de la inscripción (líns. 2-4). Si se observa el miliario de Guillena a partir del dibujo publicado por Pierre Sillières (fig. 2.3a) no parece posible la idea de reconstruir el numeral XXXI, como han considerado Canto y otros autores ${ }^{22}$, sino que me decanto por mantener la lectura de las XXI millas $(31,1 \mathrm{~km}$.). Esto implicaría considerar que el eje viario va de norte a sur y no desde Ituci (Tejada la Vieja), al oeste de Italica, como defendía la hipótesis planteada por Canto.

Respecto a la mención de la fórmula fecit, lo normal es pensar que estos cuatro miliarios hubieran pertenecido a una vía de nueva creación obsequiada por el propio Adriano ${ }^{23}$ (Canto, en HEp. 13, la apoda como via Nova Hadriana Augusta apoyándose en el miliario antequerano que reveló el nombre de la via Nova Domitiana Augusta ${ }^{24}$, aunque en el caso sevillano no se nombre expresamente). Sin embargo, existen casos en otros miliarios hispanos en los que el uso del fecit $\mathrm{o}$, incluso, fecit et restituit, no implicaría la apertura de una "via nova". Es más, el uso de fecit para

424). Todos ellos sostienen que tal caput sería el límite septentrional del territorio de Italica, cosa del todo improbable por la imposibilidad de que el miliario de Guillena tuviese un numeral mayor al miliario de Italica. Sorprende que Sillières, quien ha trabajado sobre esta zona en varias ocasiones (1982: 437-448; 1990b: 73-88), no haga propuestas al respecto, proponiendo un caput más allá de su orientación norte-sur. Por el contrario, otra teoría (sin ninguna base) coloca la milla I en Almadén de la Plata (un mínimo de 60 $\mathrm{km}$. vid. fig. 2) ya que indican que sería la mansio Mons Marmorum (It. Ant. 432.4), pero el miliario indica que está a XLVI, aunque Solana y Sagredo (2006, 60 nota 92) corrigen como XXVI para hacerlo concordar con los numerales de los miliarios (aunque no con la distancia real).

22 Hernández, Sancho y Collantes (1955); García y Bellido (1965: 23); HAE 2201.

23 Lo que sí hay que tener en cuenta es que esta vía podría haber estado financiada directamente desde las arcas imperiales, como otros proyectos urbanísticos de Italica, imposibles de costear para una ciudad de baja densidad demográfica, García y Bellido (1964: 457).

24 [Imp(erator) Cae]s(ar) Diui V[espasi]ani f(ilius) / Dom[itianus Aug(ustus) Germani]c[us pontif(ex) max]imus tribunic(ia) p[otest(ate)] [VI imp(erator) X[IIII] co(n)[s(ul)] XIII cen[sor p] erpetuus $p$ (ater) $p$ (atriae) viam /Domitianam Augustam VI $\left(\right.$ CIL II $\mathrm{II}^{2} / 5$, p. $205=$ HEp. 8, 344 = AE 2002, $746=$ HEp. 12, $451=A E$ 2004, 746). 


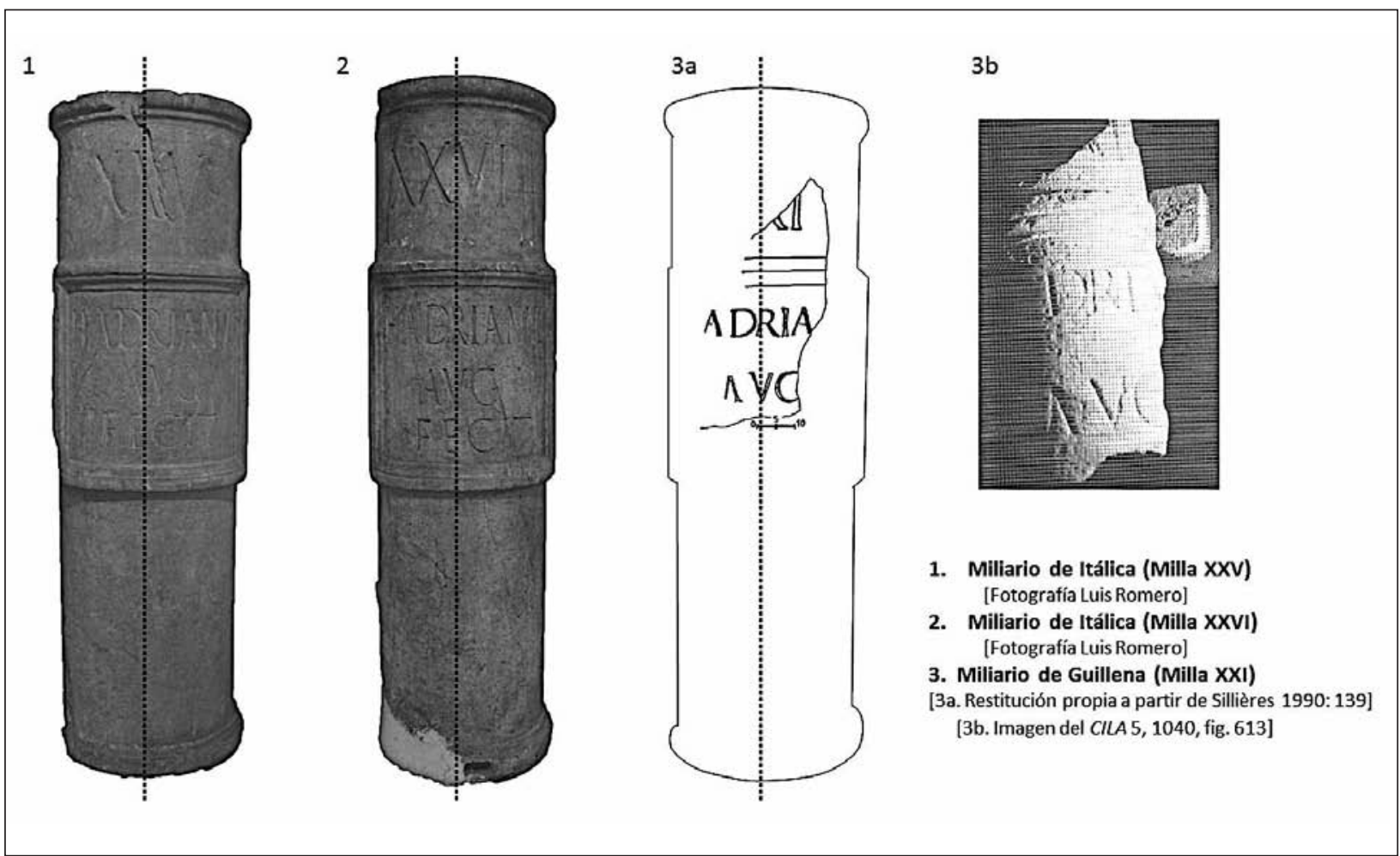

Fig. 2. Comparación de los otros 3 miliarios y sus ejes de simetría (composición propia a partir de L. Romero y P. Sillieres 1990a).

amojonar vías construidas mucho antes sólo se encuentra en miliarios de los emperadores ulpioaelios y, específicamente, de Trajano ${ }^{25}$.

Otro argumento aportado por Canto (1979: 334) para justificar la presencia de una vía de nueva construcción sería que no existía un amojonamiento previo que condicionase la vía. Hay que tener en cuenta que la apertura de una vía no necesariamente conlleva el amojonamiento como una correspondencia unívoca. Esto se aprecia cuando se mira el registro documental bético, que no muestra ningún miliario previo a Augusto, pero sería impensable hipotetizar que no se abrieron vías durante época republicana en una provin-

25 En la via a Castulone-in coloniam Acci los miliarios de Trajano CIL XVII/1, 302 (a $3 \mathrm{~km}$, de Santisteban del Puerto) y 303 (La Aldehuela, Úbeda) expresan una fórmula extraña fecit et restituit extrañando que una vía "restituida" no podía haber sido "hecha" en el mismo momento. Su editor, Schmidt, apunta a un origen haplológico debido a la mención de la patria potestad justo antes (PPFECIT) aunque a mí, personalmente, no me llega a convencer del todo, ya que en otros miliarios de la misma provincia como CIL XVII, 1, 307 la tribunicia potestas se nombra justo antes de refecit sin problema. El uso de fecit en los miliarios de Trajano de la via a Caesaraugusta per Cluniam Asturicam versus expone esta problemática más claramente. En dicha vía existe un miliario de Augusto $(C I L \mathrm{XII} / 1,224)$ que mostraría su uso en dicha época y que marca un caput en Turiaso. Sin embargo, también existen en la misma vía 6 miliarios de época de Trajano y todos ellos mencionan fecit cia con una amplia trayectoria urbana y viaria como es la Baetica. Teniendo claro esto, se puede pensar en que los miliarios pueden amojonar una vía que ya existía aunque no tuviese miliarios anteriores. Por ello, la creación de un nuevo caput se podía pensar en un lugar a elección del curator viarum que se encargase de esa labor. En el caso de los miliarios de Adriano, ese caput podría corresponder con la confluencia con un río que, además, es límite administrativo. Si hubiese habido amojonamiento previo (cosa no documentada), tampoco sería impedimento para cambiar el caput viae como pasa con los citados miliarios de Turiaso/ Augustobriga-Numantia (vid. supra).

$(225,229,231,232,233(?), 235)$ que marcan un caput a Augustobriga (diferente al de Turiaso). Este aspecto parece haber sido pasado por alto en los estudios previos, pero no hay duda de la problemática, que es similar al caso bético. El uso de fecit podría deberse a un cambio en el sistema viario y/o a una reorganización de los capita viarum, así como intervención en la propia estructura de la calzada, que, a mi modo de ver, podría haber sido el mismo caso que con los miliarios adrianeos de Guillena, el hallado fortuitamente en La Rinconada e Italica. Otro ejemplo más se encuentra en la via in Insula Baliaricum minore ab Iamnone Magonem. En este caso es más dudoso porque es un miliario transmitido por la tradición manuscrita (CIL XVII/1, 306). Si nos fiamos del dibujo, la restitución que realiza su editora Campedelli quedaría forzada con la ordinatio que se ha transmitido (aunque sin duda, se pensó acertadamente en el texto del $n^{\circ} 307$ para restituirlo). 


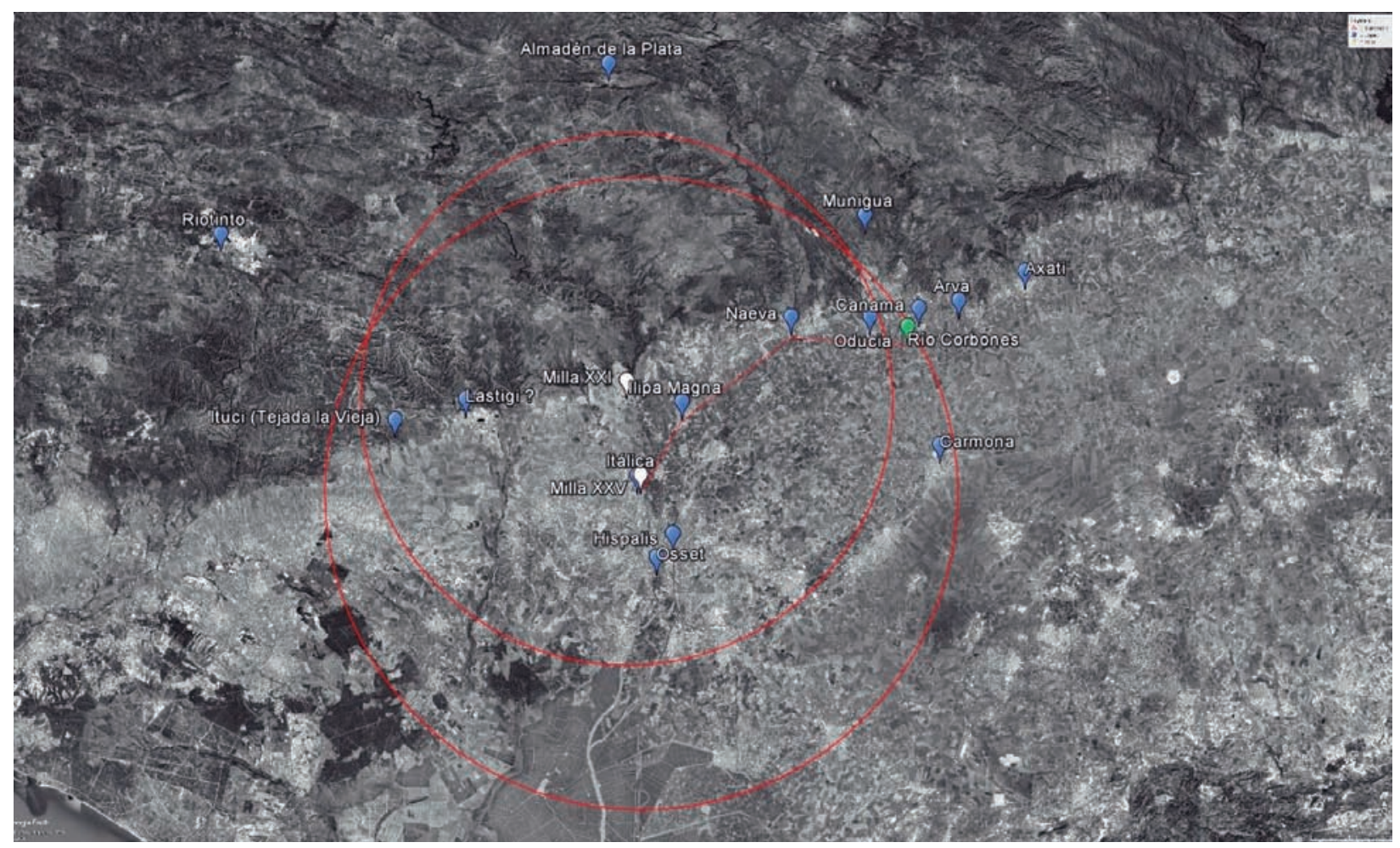

Fig. 3. Cálculo de km. máximos de los miliarios milla XXV (círculo exterior) y milla XXI (círculo interior) así como las principales ciudades relacionadas (elaboración propia a partir de Google Earth Pro).

\section{El CAPUT VIAE. UNA HIPÓTESIS}

Frente a esto, y con la debida cautela al no tener información contextual definitiva sobre este nuevo miliario, propongo una posibilidad que, a falta de nuevos datos, motive un debate al respecto e intente buscar una solución a dicho problema. Atendiendo a una progresión de norte-sur y teniendo en cuenta que el miliario de Guillena no apareció en contexto (a pesar de que, en la Antigüedad, su emplazamiento originario probablemente debió encontrarse en una vía cercana a dicha localidad), creo que podríamos estar ante una rehabilitación completa de una vía que atravesase el conventus Hispalensis trasversalmente (o al menos hasta Italica). Por ello, se debe buscar el caput hacia el noreste y no hacia el norte, según parecen indicar. No obstante, soy consciente de la fragilidad de la documentación y espero que futuros hallazgos permitan dilucidar de manera más clara un problema que se viene tratando desde hace más de un siglo para una provincia en la que no conocemos muchos capita viarum $^{26}$. Hasta entonces, estos datos que se van conociendo de manera muy sesgada no permiten dilucidar mucho más a lo enunciado, pero siempre es una alegría poder contar con otro epígrafe más que amplíe el corpus de miliarios hispanos.
Viendo el ámbito máximo al que atienden los 37 $\mathrm{km}$. del miliario que se halló posiblemente en contexto, tenemos una zona de búsqueda más limitada. Contando aproximadamente las millas, este punto inicial de la vía podría ser el paso del río Corbones o un lugar próximo a él (Oducia, si se prefiere, ya que es la ciudad más próxima). Hay que tener en cuenta que ese río es el límite de los agri de Obulcula (conventus Astigitanus) y Carmo (conventus Hispalensis) y correspondería a una vía que discurriría por la margen izquierda del Baetis. Una propuesta hipotética que, sin embargo, es la que, de momento, parecen sugerir las evidencias. Las posibilidades de Almadén de la Plata y Río Tinto quedan descartadas por lejanía y las ciudades de Canama, Arva, Munigua o Naeva no pueden ser descartadas, pero no parecen ni ser un límite ni presentar un interés preferencial para que sugieran ser un lugar en el que implantar la cabecera de una vía.

En refuerzo de esta hipótesis, es plausible argumentar que la única noticia sobre la procedencia de la milla I, aunque sin más datos, alude a algún punto dentro de la provincia de Sevilla, por lo que Ituci (Tejada la Vieja, Huelva), en esa situación, podría quedar descartada, al menos desde mi punto de vista. La sombra de la duda sólo podrá solventarse con la aparición de nue-

26 Al respecto Laing, 1908 y, más recientemente, EspañaChamorro 2017b. 
vos miliarios que corroboren definitivamente ese trazado por la provincia de Sevilla (o no)

Además, no es raro encontrar cruces de ríos como capita viarum. Tenemos el famoso Ianus Augustus emplazado sobre el Baetis a la entrada de la provincia, pero además es un tipo de práctica relativamente habitual en zonas de Italia (vid. Calzolari, 2002: 173-175) como en la via Aemilia y el río Trebbia (Piacenza), la via Claudia Augusta y el río Po o con algunos miliarios veroneses cuyo caput viae coincide con el río Pado ${ }^{27}$.

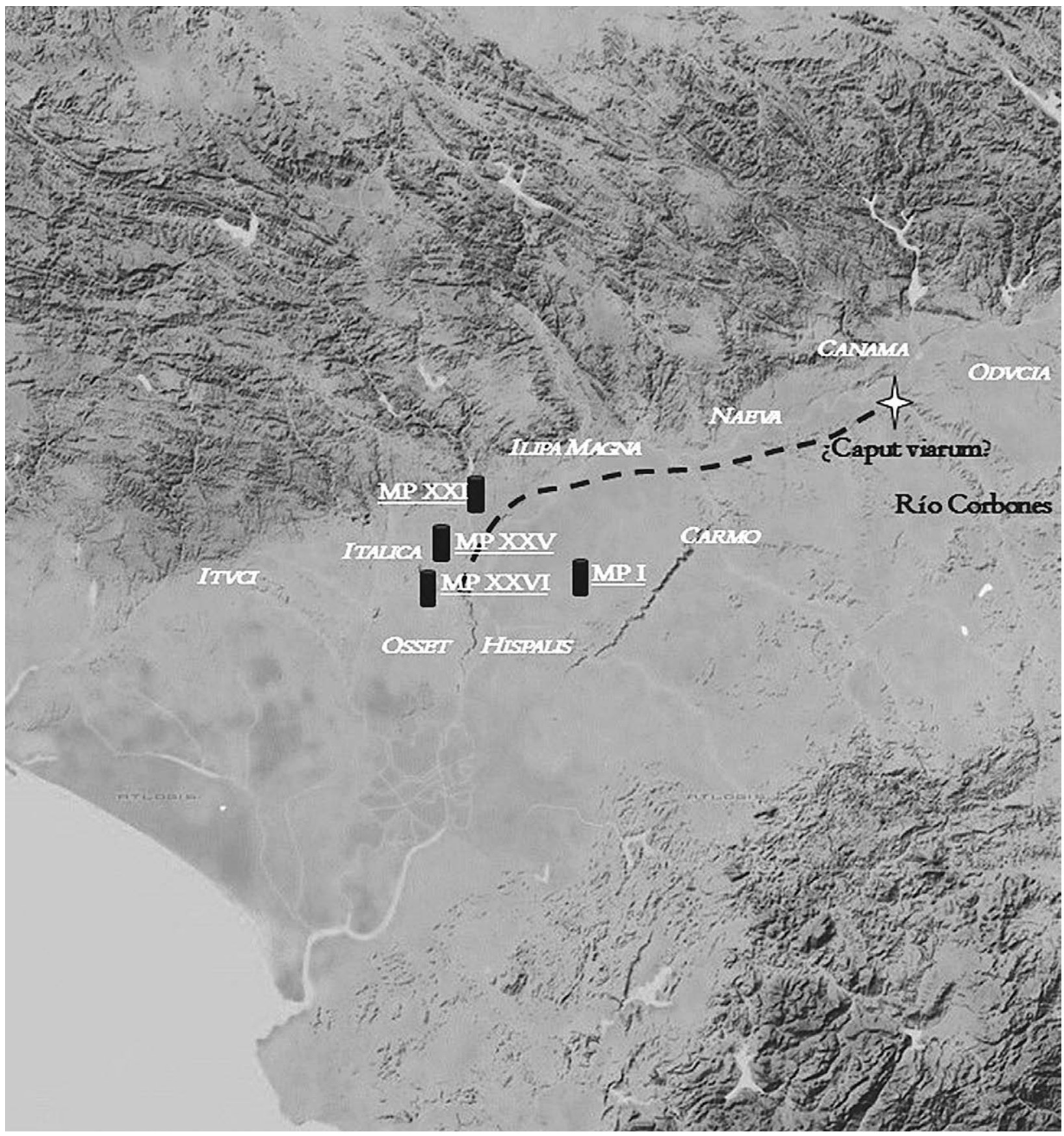

Fig. 4. Con los lugares de hallazgo de los cuatro miliarios de la serie Hadrianus Augustus fecit, Ituci, el teórico trazado de la vía amojonada y el caput viae propuesto.

(Elaboración propia sobre Atlogis).

27 Ti(berius) Claudius Caesar / Augustus German(icus) / pont(ifex) max(imus) trib(unicia) pot(estate) VI / co(n)s(ul) desig(natus) IIII imp(erator) XI p(ater) p(atriae) / [vi]am Claudiam Augustam / quam Drusus pater Alpibus / bello patefactis derexserat(!) / munit a flumine Pado at(!) / flumen Danuvium per / m(ilia) p(assuum) CC [?] CIL V, 8003 $=C I L \mathrm{XVII} / 4,1=I B R 465$. 


\section{Bibliografía}

Calzolari, M. (2002): "Il calcolo delle distanze e i fiumi come capita viarum nei miliari dell'Italia settentrionale". Orizzonti: rassegna di archeologia 3 : $169-175$

Canto De Gregorio, A.M. (1979): "El acueducto romano de Itálica". Madrider Mitteilungen 20: 283-338.

CIL XVII / 1 - Schmidt, M.G. y Campedelli, C. (2015): Corpus Inscriptionum Latinarum XVII: Miliaria Imperii Romani - Miliaria Provinciae Hispaniae Citerioris. Berlín / Boston.

CILA 3: González Fernández, J. (1989): Corpus de Inscripciones Latinas de Andalucía 3 (Volumen II, Tomo 2, La Vega -Itálica-). Sevilla.

CILA 5: González Fernández, J (1996): Corpus de Inscripciones Latinas de Andalucía 5 (Volumen II, Tomo 4, El Aljarafe, Sierra Norte, Sierra Sur Sevilla). Sevilla.

Collantes Terán, H. (1953): "Hispanorromano, Santiponce (Sevilla)". Noticiario Arqueológico Hispánico 2: $226 \mathrm{n}^{\circ} 710$.

Corzo Sánchez R.; Toscano San Gil, M. (1989): Itálica. Excavaciones en el teatro (1989). Memoria. Excavación del cuadrante norte del pórtico. Sevilla.

Corzo Sánchez, R. (1993): “El teatro de Itálica” en S.F. Ramallo Asensio y F. Santiuste de Pablos (coord.): Teatros romanos de Hispania. Cuadernos de Arquitectura romana 2. Murcia: 157-171.

ERBC = Canto De Gregorio, A.M. (1997): Epigrafía Romana de la Baeturia Céltica. Madrid.

ERIt = Canto De Gregorio, A. (1985): Epigrafía Romana de Itálica. Madrid.

Fernández Chicarro, C. (1951): El Museo Arqueológico Provincial de Sevilla. Madrid.

España-Chamorro, S. (2017a): Límites y territorios de la Bética romana. Tesis doctoral inédita. Universidad Complutense de Madrid.

España-Chamorro, S. (2017b): "Los Capita Viarum de la Baetica”. Anales de Arqueología Cordobesa 28: 11-32.

España-Chamorro, S. (2017c): "Pedagogía del poder imperial en el espacio rural bético a través de los miliarios", Potestas 10: 31-48.

España-Chamorro, S. (2017d): "Poder y Territorio. La política territorial y viaria en la Baetica de Augusto a Adriano" en VV.AA., Formas, manifestaciones y estructuras del poder político en el Mundo Antiguo. UAM Ediciones. Madrid: 333-350.

España-Chamorro, S. (2018): "Miliarios y límites provinciales: Algunas reflexiones sobre el miliario de Mengíbar CIL XVII/1 93 y la frontera oriental entre la Bética y la Citerior". Epigraphica 80: 211-228.
Fernández Chicarro, C. (1957): Catálogo del Museo Arqueológico de Sevilla. Madrid.

Fernández Chicarro, C. (1969): Catálogo del Museo Arqueológico de Sevilla. Madrid.

Fernández Chicarro, C.; Fernández Gómez, F. (1980): Catálogo del Museo Arqueológico de Sevilla. Madrid.

Fernández López, M. (1904): Excavaciones en Itálica (año 1903). Sevilla.

García y Bellido, A. (1960): Colonia Aelia Augusta Itálica. Madrid.

García y Bellido, A. (1964): Las casas de Itálica. VIII Congreso Nacional de Arqueología. Zaragoza: 454-460.

García y Bellido, A. (1965): "La Itálica de Adriano" en Les Empereurs romains d'Espagne. París: 293-298.

Hernández Díaz, J.; Sancho Corbacho, A.; Collantes de Terán F. (1955): Catálogo arqueológico y artístico de la provincia de Sevilla. Sevilla IV. Sevilla.

Luzón Nogué, J.M. (1975): “Antigüedades romanas en la Provincia de Huelva”. Huelva: Prehistoria y Antigüedad 1: 269-320.

Nierhaus, R. (1966): "Die wirtschaftlichen Voraussetzungen der Villenstadt von Italica". Madrider Mitteilungen 7: 189-205.

Rodríguez Colmenero, A.; Ferrer Sierra, S.; D. Álvarez Asorey R. (2004): Miliarios e outras inscricións viarias romanas do Noroeste Hispánico (Conventos Bracarense, Lucense e Asturicense). Lugo.

Rodríguez Gutiérrez, O. (2004): El teatro romano de Itálica. Estudio arqueoarquitéctonico. Cuadernos de la Fundación Pastor. Madrid.

Salinas de Frías M.; Palao Vicente, J.J. (2012): "Nuevo miliario de Augusto procedente de Fuenteguinaldo (Salamanca)". Archivo Español de Arqueología 85: 273-279. https://doi.org/ 10.3989/aespa.085.012.016.

Sillières, P. (1982): “Centuriation et voie romaine au sud de Mérida. Contribution à la délimitation de la Bétique et de la Lusitanie". Mélanges de la Casa de Velázquez 18: 437-448 https://doi.org/10.3406/ casa.1982.2376.

Sillières, P. (1984): "Les milliaires du sud de la péninsule ibérique" en R. Étienne (ed.) Epigraphie Hispanique. Problèmes de méthode et d'édition. París: 270-271.

Sillières, P. (1990a): Les Voies de communication de l'Hispanie méridionale. Burdeos.

Sillières, P. (1990b): "Voies romaines et limites de provinces et de cités en Lusitanie" en Les villes de Lusitanie romaine. Table ronde du CNRS (Talence, le 8-9 novembre 1988). París: 73-88. 
Sillières, P. (1994): “Le Ianus Augustus" en R. Bedon, P.M. Martin y Ch. M. Ternes (eds.) Mélanges Raymond Chevallier: Histoire \& Archéologie. Caesarodunum 28: 305-311.

Solana Sainz, J.M; Sagredo San Eustaquio, L. (2006): "La política edilicia viaria en Hispania durante el reinado de Adriano". Hispania Antiqua. 30: 35-86.

Solana Sainz, J.M; Sagredo San Eustaquio, L. (2008): La política viaria en Hispania: siglos I-II d.C. Valladolid.
Stylow, A.U.; Atencia Paez, R.; Vera Rodríguez, J. (2004a): "Via Domitiana Augusta" en Siedlung und Verkehr im römischen Reich: Römerstraßen zwischen Herrschaftssicherung und Landschaftsprägung; Akten des Kolloquiums zu Ehren von Prof. H. E. Herzig vom 28. und 29. Juni 2001 in Bern. Berna: 361-378.

Stylow, A.U.; Atencia Paez, R.; Vera Rodríguez, J. (2004b): "Via Domitiana Augusta". Mainake 26: 417-430. 